\title{
lodine- 125 radiolabeling of silver nanoparticles for in vivo SPECT imaging
}

This article was published in the following Dove Press journal:

International Journal of Nanomedicine

3I August 2010

Number of times this article has been viewed

\section{Adrian Chrastina Jan E Schnitzer}

Proteogenomics Research Institute for Systems Medicine, San Diego, CA, USA

Correspondence: Jan E Schnitzer Proteogenomics Research Institute for Systems Medicine, I I 107 Roselle St., San Diego, CA 92121, USA

Email: jschnitzer@prism-sd.org

\begin{abstract}
Silver nanoparticles are increasingly finding applications in medicine; however, little is known about their in vivo tissue distribution. Here, we have developed a rapid method for radiolabeling of silver nanoparticles with iodine-125 in order to track in vivo tissue uptake of silver nanoparticles after systemic administration by biodistribution analysis and single-photon emission computerized tomography (SPECT) imaging. Poly $(N$-vinyl-2 -pyrrolidone)-capped silver nanoparticles with an average size of $12 \mathrm{~nm}$ were labeled by chemisorption of iodine- 125 with a $>80 \%$ yield of radiolabeling efficiency. Radiolabeled silver nanoparticles were intravenously injected in Balb/c mice, and the in vivo distribution pattern of these nanoparticles was evaluated by noninvasive whole-body SPECT imaging, which revealed uptake of the nanoparticles in the liver and spleen. Biodistribution analysis confirmed predominant accumulation of the silver nanoparticles in the spleen $(41.5 \% \mathrm{ID} / \mathrm{g})$ and liver $(24.5 \% \mathrm{ID} / \mathrm{g})$ at $24 \mathrm{~h}$. Extensive uptake in the tissues of the reticuloendothelial system suggests that further investigation of silver nanoparticle interaction with hepatic and splenic tissues at the cellular level is critical for evaluation of the in vivo effects and potential toxicity of silver nanoparticles. This method enables rapid iodine-125 radiolabeling of silver nanoparticles with a specific activity sufficient for in vivo imaging and biodistribution analysis.
\end{abstract}

Keywords: Ag nanoparticles, radiolabeling, PVP, CT-SPECT imaging

\section{Introduction}

Silver nanoparticles (Ag NPs) have attracted much attention recently because of their broad-spectrum antimicrobial activities. Ag NPs have therefore found extensive medical applications in catheter coatings, ${ }^{1}$ wound dressings, ${ }^{2}$ and antimicrobial creams and lotions. ${ }^{3}$ Furthermore, because of the antibacterial effects of Ag NPs, these particles are currently utilized in a variety of everyday products, including laundry detergents, water purificants, washing machines, deodorants, floor coatings, wall paints, textiles, containers, shower curtains, and tabletops. ${ }^{4-6}$ Colloidal silver has even been promoted as an oral supplement to prevent and treat many diseases. ${ }^{7}$ Multiple therapeutic applications and extensive utilization of Ag NPs in surface coatings inherently lead to environmental and/or internal exposure of the human body to these nanoparticles. However, little is known about in vivo trafficking and deposition of Ag NPs. A few studies have reported very limited data on Ag NP accumulation in organs, with relevant toxicological implications. ${ }^{8,9}$ Biocompatibility of Ag NPs may be a serious concern because several studies have shown that Ag NPs have cytotoxic and genotoxic effects on human cells. ${ }^{10,11}$ In addition, exposure to 
Ag NPs is associated with proinflammatory responses; ${ }^{12}$ altered gene expression in brain tissues, indicating possible neurotoxicity; ${ }^{13}$ and even potential liver damage. ${ }^{9}$ Furthermore, Ag NPs induced developmental defects in zebrafish embryos. ${ }^{14,15}$ Despite the widespread application of Ag NPs and growing evidence of their potential toxicity, no studies have evaluated the primary targets and organ distribution pattern of Ag NPs following systemic administration. However, several studies have indicated the propensity of Ag NPs to translocate into circulation after pulmonary ${ }^{16-18}$ and dermal exposure. ${ }^{19,20}$ Thus, there is an escalating need for the development of methods for direct imaging and tracking of Ag NPs in vivo.

Here, we have developed a technique for the rapid radiolabeling of Ag NPs with ${ }^{125} \mathrm{I}$-iodine. After systemic administration, the distribution pattern of ${ }^{125} \mathrm{I}$ isotopetagged Ag NPs was traced in vivo by gamma-scintigraphic imaging, and tissue uptake was quantified by biodistribution analysis.

\section{Experimental methods}

\section{Materials and animals}

$\mathrm{AgNO}_{3}$ was purchased from Alfa Aesar (Ward Hill, MA). Iodobeads were obtained from Pierce (Rockford, IL). Prepacked Sephadex G-25 columns were acquired from GE Healthcare (Uppsala, Sweden). Carrier-free iodine-125 was purchased from Perkin Elmer (Boston, MA). All other chemicals were obtained from Sigma-Aldrich (St Louis, MO). Nanopure water $\left(>18.0 \mathrm{M} \Omega \mathrm{cm}^{-1}\right)$ purified with the Millipore Milli-Q system was used in all the experiments.

All animal experiments were carried out in accordance with protocols approved by the Institutional Animal Care and Use Committee (IACUC). Animals were housed in the animal care facility, and the animals that received radiolabeled nanoparticles were housed and imaged in a separate, lead-shielded animal facility. Balb/c mice (females, $25 \mathrm{~g}$, 6-8 wks) were purchased from Jackson Laboratories (Sacramento, CA) and Fisher CDF rats (females, $125 \mathrm{~g}$ ) were obtained from Charles River Laboratories (Wilmington, MA).

\section{Synthesis of Ag NPs}

Ag NPs were synthesized as described previously ${ }^{21}$ with minor modifications. Poly( $N$-vinyl-2-pyrrolidone, $\mathrm{MW}$ 40,000) (PVP-40T) was used as a stabilizer and also as a weak reducing agent. In brief, $1 \mathrm{mM} \mathrm{AgNO}_{3}$ in the presence of $1 \mathrm{mM}$ PVP-40T, $\mathrm{pH} 8.8$, was stirred at $60^{\circ} \mathrm{C}$ for $5 \mathrm{~min}$. The reaction vessel was then cooled on ice for $20 \mathrm{~min}$. Thereafter, the nanoparticles were separated by centrifugation at $20,000 \mathrm{~g}$ for $30 \mathrm{~min}$ (Beckman L8-M ultracentrifuge) at $4^{\circ} \mathrm{C}$. The pellet was then resuspended in $10 \mathrm{mM}$ 4-(2-hydroxyethyl) piperazine-1-ethanesulfonic acid (HEPES), pH 6.0, and centrifuged again to remove contaminants.

\section{Radiolabeling of Ag nanoparticles with iodine- 125}

Chloramine-T ( $N$-chlorobenzenesulfonamide) immobilized on a polystyrene backbone (Iodobeads; Thermo Fisher, Rockford, IL) was used as an oxidizer and incubated with $1 \mathrm{mCi}$ of carrier-free $\mathrm{Na}^{125} \mathrm{I}$ (Perkin Elmer) at room temperature for $10 \mathrm{~min}$. The solution was then removed and added to a dispersion of unfunctionalized Ag nanoparticles (2.5 mg Ag) in $10 \mathrm{mM}$ HEPES, pH 6.0, under rapid agitation with a vortex. From this step forward, the samples were protected from light with aluminum foil. The mixture was then incubated at room temperature for $30 \mathrm{~min}$ on an orbital shaker (Labquake shaker; Labindustries, Berkeley, CA) at $10 \mathrm{rpm}$. Unbound iodide-125 was removed by size exclusion chromatography on Sephadex G-25 columns (GE Healthcare); $10 \mathrm{mM}$ HEPES, pH 6.0, was used as an elution buffer. More than 95\% of Ag NPs was recovered after elution as determined from spectral measurements A (410 nm).

\section{Characterization of nanoparticles}

Nanoparticle formulations were analyzed for size distribution by transmission electron microscopy (TEM) and photon correlation spectroscopy by using an N5 Submicron Particle Size Analyzer (Beckman Coulter, Miami, FL). For TEM, samples were dried on formvar-coated copper grids (Ted Pella, Redding, CA) and analyzed using a Morgagni 268 D electron microscope equipped with a MegaView III digital camera. The ultraviolet-visible absorption spectra were recorded using a DU 640 spectrophotometer (Beckman Coulter, Fullerton, CA). Dark-field images were acquired using a real-time microscope (RTM)-3 optical setup equipped with Richardson contrast (Richardson Technologies, Toronto, Canada).

\section{In vivo biodistribution and computed tomography coregistered with single- photon emission computerized tomography imaging}

$\mathrm{Balb} / \mathrm{c}$ mice were intravenously injected with $4 \mu \mathrm{Ci}$ of the ${ }^{125} \mathrm{I}-\mathrm{Ag}$ NP dispersion. Mice were anesthetized by intraperitoneal injection of a mixture of ketamine $(50 \mathrm{mg} / \mathrm{kg})$ and xylazine (10 mg/kg), and computed tomography coregistered with 
single-photon emission computerized tomography (CTSPECT) imaging was performed at different time points. CT-SPECT scans were acquired using an X-SPECT second generation MicroSPECT ${ }^{\circledR}$ imaging system (Gamma Medica, Inc., Northridge, CA). SPECT images were obtained in a $360^{\circ}$ orbit with 30 -s sampling every $6^{\circ}$ with low energy, high-resolution parallel hole collimators and the pulse-height analyzer window set over the $30 \mathrm{keV}$ photopeak of iodine- 125 . Tomographic reconstruction was performed using a standard filtered back projection. Three-dimensional data sets after CTSPECT fusion were processed on the AMIRA System (TGS, Inc., San Diego, CA). For biodistribution analysis, mice were sacrificed and the lung, liver, spleen, heart, colon, stomach, esophagus, muscle, brain, kidney, and pancreas were excised, scanned, and analyzed in the planar mode for $5 \mathrm{~min}$. Radioactivity of preweighed tissue samples was measured using the CobraII Auto-Gamma counter (Packard, Meriden, CT). Uptake values were corrected for radiodecay and expressed as a percentage of the injected dose per gram of tissue $(\% \mathrm{ID} / \mathrm{g})$. Fisher CDF rats were intravenously injected with $20 \mu \mathrm{Ci}$ of ${ }^{125} \mathrm{I}-\mathrm{Ag}$ NPs and CT-SPECT images were acquired at the indicated time points.

\section{Results}

\section{Synthesis, characterization,} and radiolabeling of $\mathrm{Ag}$ NPs

Ag NPs were synthesized by reduction of silver nitrate using PVP as a polymer capping agent (see Exp. Methods).
A colloidal dispersion of Ag NPs was radiolabeled by chemisorption of elemental iodine onto the metal surface. Free radioisotope was removed from the radiolabeled Ag NPs by size exclusion chromatography. The content of the free iodine in the sample was less than $0.5 \%$, as estimated by analysis of the activity of the supernatant after centrifugation. The yield of radiolabeling was above $80 \%$, with a specific activity of $0.4-0.6 \mu \mathrm{Ci} / \mu \mathrm{g}$ of ${ }^{125} \mathrm{I}-\mathrm{Ag}$ NPs. Size analysis of radiolabeled nanoparticles by photon correlation spectroscopy (PCS) revealed a relatively narrow size distribution; the sizes of $85 \%$ of the particles were within the range $9-16 \mathrm{~nm}$, with an average size of $12 \mathrm{~nm}$ (Figure 1A). TEM confirmed this size distribution pattern (Figure 1B). TEM revealed that the particles were spherical; further, it provided the actual size of the electron-dense metallic part of the nanoparticles. PCS analysis, on the other hand, provided the hydrodynamic radius of PVP-capped ${ }^{125} \mathrm{I}-\mathrm{Ag}$ NPs. Radiolabeled Ag NPs exhibited light-scattering under dark field microscopy (Figure 1C) and showed strong surface plasmon resonance in the visible spectrum, ie, $\lambda_{\text {max }}=410 \mathrm{~nm}$ (Figure 1D). The characteristic plasmon band of Ag NPs was unaltered after chemisorption of iodine-125 to the surface of Ag NPs.

\section{In vivo imaging and biodistribution analysis of ${ }^{125} \mathrm{I}-\mathrm{Ag}$ NPs}

In order to evaluate the tissue distribution pattern of Ag NPs in vivo, radiolabeled Ag NPs were intravenously injected as a bolus dose. Then gamma-scintigraphic images were acquired,
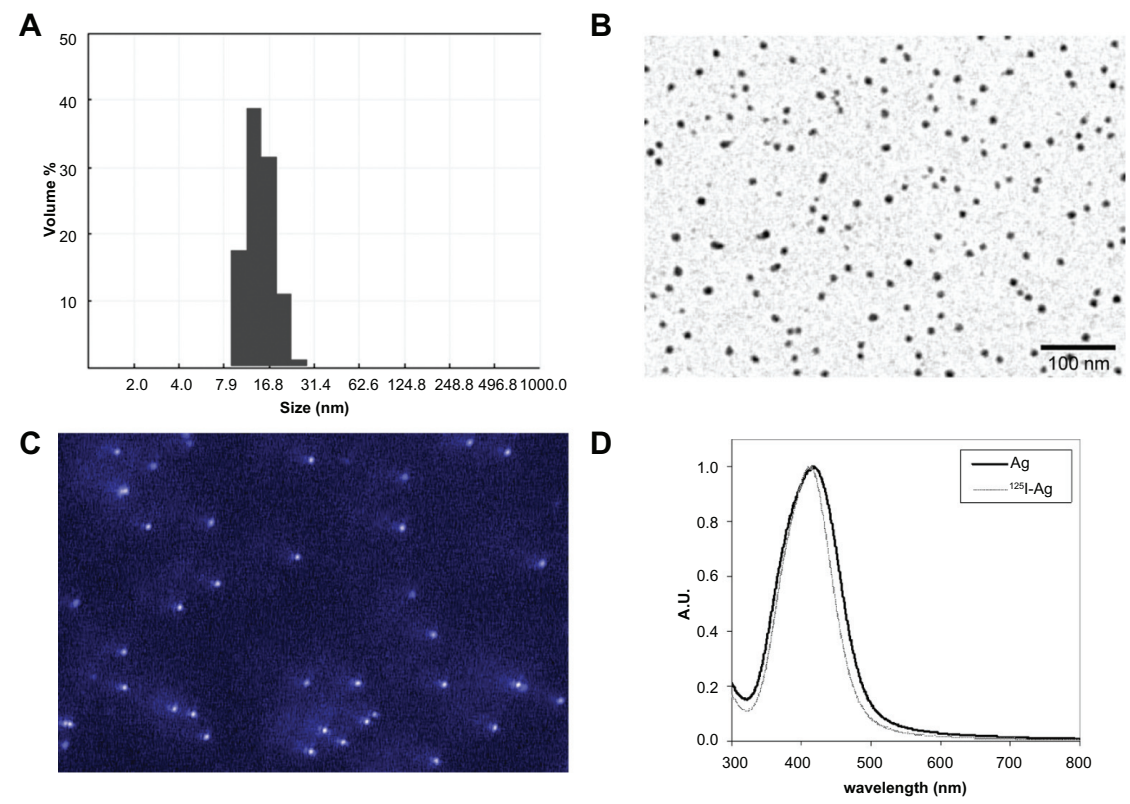

Figure I Characterization of synthesized silver nanoparticles (Ag NPs). A) Size distribution profile of ${ }^{125}$ I-Ag NPs as analyzed by photon correlation spectroscopy. B) Transmission electron microscopy (TEM) of ${ }^{125}$ I-Ag NPs. C) Light scattering as observed under a dark field real-time microscope (RTM). D) Absorption spectroscopy comparing Ag NPs and ${ }^{125} \mathrm{I}-\mathrm{Ag}$ NPs showed that the characteristic plasmon band for Ag NPs was not significantly altered after radiolabeling. 
and tissue uptake was analyzed $24 \mathrm{~h}$ later. We used SPECT imaging to analyze the spatial pattern of in vivo trafficking at the whole-body level. Acquisition of coregistered CT and SPECT images enabled us to correlate functional SPECT images of the spatial distribution of the ${ }^{125} \mathrm{I}-\mathrm{Ag}$ NPs with the anatomical information acquired by CT. CT-SPECT imaging revealed a strong ${ }^{125} \mathrm{I}-\mathrm{Ag}$ NP signal in the abdominal area, particularly, in the liver and spleen (Figure 2). The distribution of ${ }^{125} \mathrm{I}-\mathrm{Ag}$ NPs in the tissues was analyzed by planar gammascintigraphic imaging of dissected organs, and the distribution was further quantified by measurement of radioactivity. Planar imaging of dissected tissue samples confirmed a strong ${ }^{125} \mathrm{I}-\mathrm{Ag}$ NP signal in the liver and spleen (Figure 3). Biodistribution analysis revealed that ${ }^{125} \mathrm{I}-\mathrm{Ag}$ NPs mainly accumulated in the liver $(24.5 \% \mathrm{ID} / \mathrm{g})$ and spleen $(41.5 \% \mathrm{ID} / \mathrm{g})$ (Table 1$)$. Relatively low uptakes were noted in the lungs and bone: $3.8 \% \mathrm{ID} / \mathrm{g}$ and $1.5 \% \mathrm{ID} / \mathrm{g}$, respectively. Low levels of ${ }^{125} \mathrm{I}-\mathrm{Ag} \mathrm{NP}$ in the blood $(0.18 \% \mathrm{ID} / \mathrm{g})$ were due to the clearance of ${ }^{125} \mathrm{I}-\mathrm{Ag}$ NPs from circulation by the reticuloendothelial system (RES). All other tissues (ie, tissues of the urinary bladder, stomach, kidney, esophagus, pancreas, skin, colon, heart, muscle, and brain) also showed a minimal uptake $(<1 \% \mathrm{ID} / \mathrm{g})$.

Additionally, to show that RES uptake of ${ }^{125} \mathrm{I}-\mathrm{AgNPs}$ is not species limited, we performed CT-SPECT imaging in rats (Figure 4). Imaging at different time points ( $0 \mathrm{~min}, 4 \mathrm{~h}$, and $24 \mathrm{~h}$ ) after intravenous administration confirmed significant uptake by the liver. Thyroid uptake was negligible at $30 \mathrm{~min}$ and $4 \mathrm{~h}$ after injection, but it became apparent at $24 \mathrm{~h}$, indicating that the radiolabeled nanoparticles were catabolically dehalogenated.

\section{Discussion}

Despite widespread application of Ag NPs in the biomedical field ${ }^{1,2,22}$ and in consumer products, ${ }^{4,6}$ there are limited in vivo data regarding the biodistribution, organ deposition, and potential toxicity of Ag NPs. ${ }^{8,9}$ Ag NPs have been used as carriers of lanthanide complexes for designing potential nanoscale magnetic resonance imaging (MRI) contrast agents, ${ }^{23}$ and the use of Ag NPs-caged silica particles has been explored for ultrasonographic and photoacoustic imaging of pancreatic cancer in isolated perfused organs. ${ }^{24}$ Surfaceenhanced Raman scattering (SERS)-active silver colloids were used as plasmonic nanoprobes for in vitro biosensing and imaging. ${ }^{25}$ Besides these bioimaging-related studies, to the best of our knowledge, no reports exist on in vivo imaging of Ag NPs at the whole-body level.

Studies on rodent models indicate organ toxicity of Ag NPs. ${ }^{9,13}$ There are several although limited reports on the tissue distribution of Ag NPs after pulmonary exposure via inhalation. ${ }^{16-18}$ These studies indicate that Ag NPs may translocate from the site of exposure and accumulate in secondary targets, including the liver, spleen, and brain, after pulmonary exposure; this translocation presumably occurs via blood circulation or by transport within neurons. However, it is not completely clear if the silver accumulation in these tissues was due to the translocation of particles or released ions since the methods used in these studies do not distinguish between Ag NPs and ions.

Clinical studies evaluating absorption and systemic availability of Ag NPs from a burn wound dressing revealed elevated serum silver levels after dermal exposure. ${ }^{19,20}$

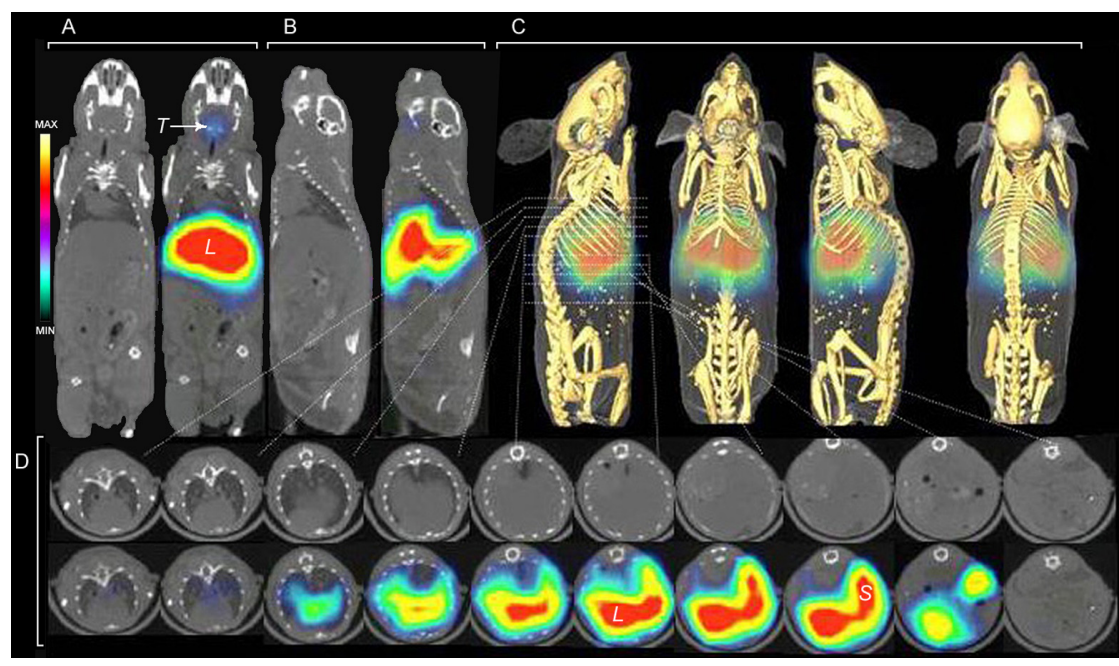

Figure 2 Whole-body computed tomography coregistered with single-photon emission computerized tomography (CT-SPECT) imaging of ${ }^{125}$ I-Ag NPs localization in mouse $24 \mathrm{~h}$ after injection. Panels A, B, and D show computed tomography (CT) scans and corresponding fused CT-SPECT images. Panel A depicts coronal slices and panel B, sagittal slices. Panel D shows axial slices along the indicated area of the thoracic and abdominal cavity. Panel $C$ shows a 3-D image after fusion of volumetric SPECT texture with the CT isosurface. Positions of the organs with accumulated radioactivity are indicated: liver (L), spleen (S), and thyroid (T). 


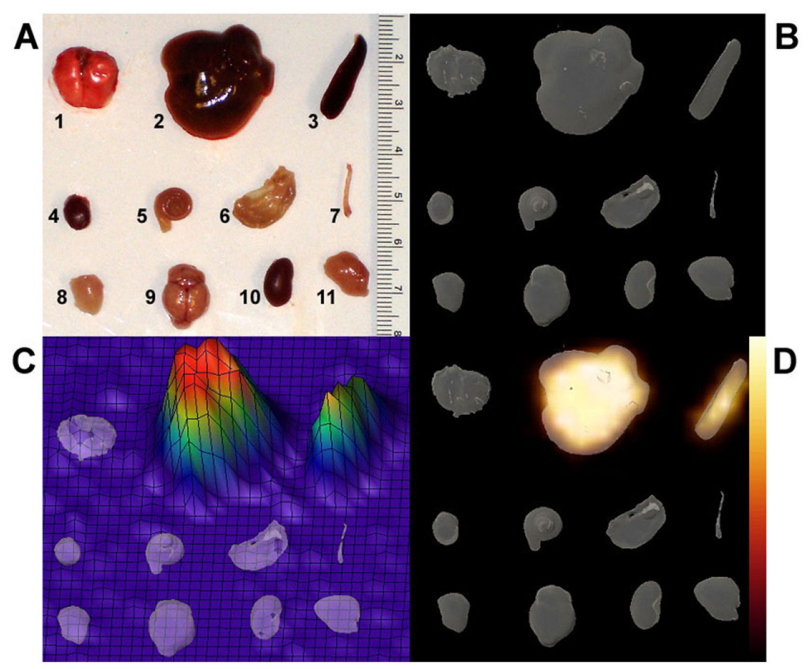

Figure 3 Biodistribution of ${ }^{125} \mathrm{I}-\mathrm{Ag}$ NPs in mouse $24 \mathrm{~h}$ after intravenous administration $(4 \mu \mathrm{Ci} ; 0.4 \mu \mathrm{Ci} / \mu \mathrm{g})$. A) Photograph of dissected tissues. B) 3D isosurface reconstruction of CT data. C and D) CT-SPECT fusion of dissected tissues. Tissues: I, lung; 2, liver; 3, spleen; 4, heart; 5, colon; 6, stomach; 7, esophagus; 8, muscle; 9, brain; 10, kidney; II, pancreas.

In one of these studies, ${ }^{19}$ increased liver enzyme levels were observed, indicating that liver injury had occurred during treatment. After the Ag NP-based wound dressings were removed, liver function returned to normal, thus linking Ag NPs to liver toxicity. However, this link between silver ions and liver toxicity should be carefully considered.

In general, after intravenous administration of nanoparticulate systems, the nanoparticles are taken up by the RES (phagocytic system of the liver and spleen), leading to clearance of the nanoparticles from the systemic circulation. ${ }^{26}$ This uptake is primarily attributed to resident macrophage populations in the tissues, resulting in an inflammatory response. ${ }^{27}$ After systemic administration of nanoparticles, prominent

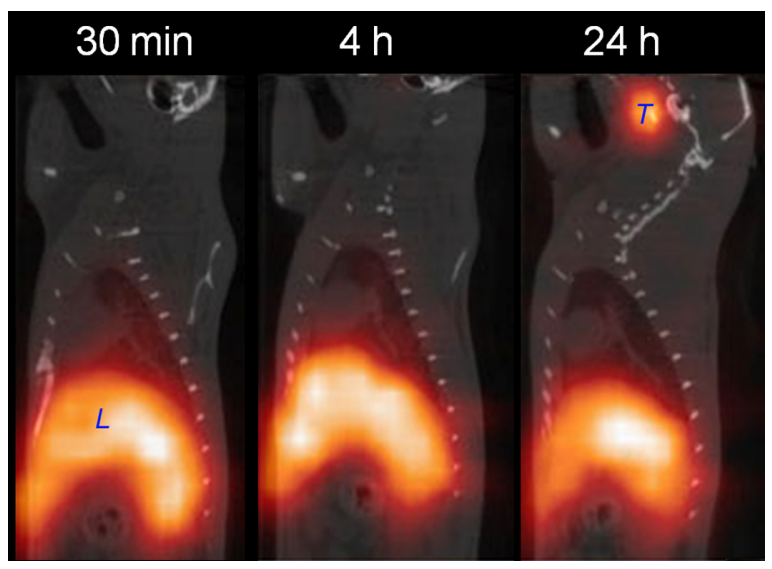

Figure 4 CT-SPECT images of iodine- 125 labeled silver nanoparticles in rats at different time points after intravenous administration. Sagittal slices are shown. Injected dosage: $20 \mu \mathrm{Ci}$ at a specific activity $0.6 \mu \mathrm{Ci} / \mu \mathrm{g}$. Positions of the liver (L) and thyroid $(\mathrm{T})$ are indicated. uptake of nanoparticles of different sizes and compositions was noted in the RES. For example, studies of gold nanoparticles ( $1.4 \mathrm{~nm}$ and $18 \mathrm{~nm}, 24 \mathrm{~h}),{ }^{28}{ }^{99 \mathrm{~m}}$ Tc-labeled latex particles of different sizes (61-660 nm, $2 \mathrm{~h}),{ }^{29}$ and gold core and silica shell nanoparticles (120 nm, $2 \mathrm{~h})$ reported superior uptake of these particles in the liver, ${ }^{30}$ and studies of ${ }^{64} \mathrm{Cu}$-labeled CdTe (12 nm, 2-6 min) quantum dot nanoparticles ${ }^{31}$ and gold nanoparticles $(10,50,100 \text {, and } 250 \mathrm{~nm} ; 24 \mathrm{~h})^{32}$ showed predominant uptake of these nanoparticles in the liver and spleen. A recent study revealed that ultrafine Ag NPs (2 nm) capped with bovine serum albumin (BSA) accumulated in the liver, spleen, and heart. ${ }^{8}$ In vivo uptake of these nanoparticles, particularly in the heart, might be mediated by the albumin receptor gp60 (albondin), which is expressed on the vascular endothelium. ${ }^{33}$

It has been suggested that modification of the nanoparticle surface with hydrophilic polymers such as polyethylene glycol (PEG) might delay recognition and uptake by the RES and influence the biodistribution profile and clearance kinetics. However, even PEGylated nanoparticles exhibit a high affinity for the RES. ${ }^{27,31}$ In the case of 13-nm PEGcoated Au NPs, uptake was primarily noted in the liver and spleen and was associated with acute inflammation and apoptosis in the liver. ${ }^{27}$ Nevertheless, grafting of hydrophilic polymers may expand surface chemistry for retargeting of nanoparticles by attachment of specific probes (antibodies, aptamers, peptides, etc.).

By using biodistribution analysis and CT-SPECT imaging, we studied the tissue uptake of ${ }^{125}$ I-labeled Ag NPs after systemic administration (100\% bioavailability) in mice. Noninvasive CT-SPECT has been previously used for small animal imaging to analyze tissue-specific accumulation of ${ }^{125}$ I-labeled probes. ${ }^{34,35}$ The biodistribution data (Table 1) and in vivo CT-SPECT imaging (Figure 2) revealed that the uptake of Ag NPs was highest in the liver and spleen. The radioactivity in these tissues was due to the uptake of ${ }^{125} \mathrm{I}-\mathrm{Ag}$ NPs and not free iodine-125. Free iodine is taken up rapidly by the thyroid gland, salivary gland, and stomach. ${ }^{36}$ We observed minor thyroid uptake at $24 \mathrm{~h}$ in mice, probably because of catabolism of ${ }^{125} \mathrm{I}-\mathrm{Ag}$ NPs and release of free iodine. Low levels of uptake in the lung might be attributable to the phagocytic activity of pulmonary macrophages. Furthermore, confirmatory extensive RES uptake was also observed at all analyzed time points in rats. High uptake of Ag NPs in the RES, particularly, in the liver, observed in our study implicates Ag-NPs-associated toxicity towards hepatic tissue. In fact, Ag NPs are highly toxic to rat liver cells in vitro, ${ }^{37}$ and chronic exposure (oral administration) 
Table I Biodistribution analysis of ${ }^{125} \mathrm{I}-\mathrm{Ag}$ NP uptake in vivo. Balb/c mice $(n=4)$ were intravenously injected with ${ }^{125} \mathrm{I}-\mathrm{Ag}$ NPs $(4 \mu \mathrm{Ci})$ and the uptake was analyzed $24 \mathrm{~h}$ later. Values were corrected for radiodecay and expressed as \%ID/g along with the corresponding standard deviation

\begin{tabular}{lc}
\hline Organ & $\%$ ID/g \\
\hline Blood & $0.18 \pm 0.11$ \\
Liver & $24.5 \pm 2.5$ \\
Spleen & $41.5 \pm 7.5$ \\
Lungs & $3.8 \pm 0.5$ \\
Bone & $1.5 \pm 0.3$ \\
U. bladder & $0.87 \pm 0.36$ \\
Stomach & $0.71 \pm 0.32$ \\
Kidney & $0.27 \pm 0.17$ \\
Esophagus & $0.26 \pm 0.05$ \\
Pancreas & $0.20 \pm 0.09$ \\
Skin & $0.16 \pm 0.08$ \\
Colon & $0.14 \pm 0.06$ \\
Heart & $0.13 \pm 0.04$ \\
Muscle & $<0.1$ \\
Brain & $<0.1$ \\
\hline
\end{tabular}

of rats to Ag NPs can lead to liver damage. ${ }^{9}$ Liver injury has also been observed after dermal exposure during treatment with Ag NP-based wound dressings. ${ }^{19}$ These reports along with our results indicate that Ag NPs have high propensity for the liver, leading to hepatotoxic consequences.

Liver-specific accumulation of Ag NPs though hypothetically beneficial for the treatment of antibiotic-resistant bacterial liver infections that might otherwise require liver resection; ${ }^{38}$ however, the potential toxicity of Ag NPs must be taken into account before these nanoparticles are applied in a clinical setting.

In our study, we used the ${ }^{125} \mathrm{I}$ - isotope of iodine for radiolabeling. This isotope is used mainly for in vitro assays, and it has recently been used in vivo for small animal imaging. Other radioisotopes of iodine, including ${ }^{123} \mathrm{I},{ }^{124} \mathrm{I}$, and ${ }^{131} \mathrm{I}$, can similarly be used for radiolabeling of Ag NPs since they have the same chemical properties. Their specific emission properties have been exploited for radiotherapy $\left({ }^{131} \mathrm{I}\right)$, SPECT imaging ( ${ }^{123} \mathrm{I}$ and ${ }^{131} \mathrm{I}$ ), and positron-emission tomographic imaging $\left({ }^{124} \mathrm{I}\right)$. Therefore, radiolabeling using other iodine radioisotopes extends the radiotherapeutic and/or imaging potential of this technique. Since ${ }^{131} \mathrm{I}$ and ${ }^{125} \mathrm{I}$ isotopes have been used efficiently for tumor radiotherapy thus targeting or intracavitary brachytherapy seeding of ${ }^{131} \mathrm{I}$ - or ${ }^{131} \mathrm{I}$-radiolabeled Ag NPs may be potentially used as nanocarriers for irradiation, especially for the treatment of liver cancer. Various radiolabeled agents selectively accumulate in the liver after intrahepatic arterial infusion, and these agents have been clinically studied to determine their possible application in internal radiation therapy of unresectable hepatocellular carcinoma. These include ${ }^{90} \mathrm{Y}$-microspheres, ${ }^{39}{ }^{188} \mathrm{Rh}$-conjugated lipiodol, ${ }^{40}$ and ${ }^{131}$ I-labeled lipiodol. ${ }^{41}$ Combining radiation doses delivered by ${ }^{131} \mathrm{I}$ - or ${ }^{125} \mathrm{I}$-labeled Ag NPs with the reactive oxygen species cytotoxicity associated with Ag NPs could, in theory, provide a synergistic therapeutic outcome.

In conclusion, we have developed a rapid and simple method to radiolabel Ag NPs with the iodine-125 isotope. We have demonstrated the utility of this technique for in vivo Ag NP tracking by biodistribution analysis and SPECT imaging. Our results showed prominent uptake of Ag NPs in the liver and spleen after intravenous administration. This finding implicates possible hepatotoxic consequences of Ag NPs and may warrant further toxicology study.

\section{Acknowledgments}

This work was supported by an RO1 CA 119378 grant from NCI. We would like to thank to Dr Halina Witkiewicz (Imaging facility, Proteogenomics Research Institute for Systems Medicine) for the technical assistance for TEM analysis. The authors report no conflicts of interest in this work.

\section{References}

1. Samuel U, Guggenbichler JP. Prevention of catheter-related infections: the potential of a new nano-silver impregnated catheter. Int JAntimicrob Agents. 2004;Suppl 1:S75-S78.

2. Chen J, Han CM, Lin XW, Tang ZJ, Su SJ. Effect of silver nanoparticle dressing on second degree burn wound. Zhonghua Wai Ke Za Zhi. 2006; 44:50-52.

3. Keck CM, Schwabe K. Silver-nanolipid complex for application to atopic dermatitis skin: rheological characterization, in vivo efficiency and theory of action. J Biomed Nanotechnol. 2009;5(4):428-436.

4. Cheng D, Yang J, Zhao Y. Antibacterial materials of silver nanoparticles application in medical appliances and appliances for daily use. Chin Med Equip J. 2004;4:26-32.

5. Sreekumar TV, Das A, Chandra L, Srivastava A, Rao KU. Inherently colored antimicrobial fibers employing silver nanoparticles. J Biomed Nanotechnol. 2009;5(1):115-120

6. Vigneshwaran N, Kathe AA, Varadarajan PV, Nachane RP, Balasubramanya RH. Functional finishing of cotton fabrics using silver nanoparticles. J Nanosci Nanotechnol. 2007;(6):1893-1897.

7. Fung MC, Bowen DL. Silver products for medical indications: riskbenefit assessment. J Toxicol Clin Toxicol. 1996;34(1):119-126.

8. Garza-Ocañas L, Ferrer DA, Burt J, et al. Biodistribution and long-term fate of silver nanoparticles functionalized with bovine serum albumin in rats. Metallomics. 2010;2:204-210.

9. Kim YS, Kim JS, Cho HS, et al. Twenty-eight-day oral toxicity, genotoxicity, and gender-related tissue distribution of silver nanoparticles in Sprague-Dawley rats. Inhal Toxicol. 2008;20(6):575-583.

10. Ahamed M, Karns M, Goodson M, et al. DNA damage response to different surface chemistry of silver nanoparticles in mammalian cells. Toxicol Appl Pharmacol. 2008;233(3):404-410.

11. Asharani PV, Low Kah Mun G, Hande MP, Valiyaveettil S. Cytotoxicity and genotoxicity of silver nanoparticles in human cells. ACS Nano. 2009;3(2):279-290.

12. Carlson C, Hussain SM, Schrand AM, et al. Unique cellular interaction of silver nanoparticles: size-dependent generation of reactive oxygen species. J Phys Chem B. 2008;112(43):13608-13619. 
13. Rahman MF, Wang J, Patterson TA, et al. Expression of genes related to oxidative stress in the mouse brain after exposure to silver-25 nanoparticles. Toxicol Lett. 2009;187(1):15-21.

14. Asharani PV, Wu YL, Gong Z, Valiyaveettil S. Toxicity of silver nanoparticles in zebrafish models. Nanotechnology. 2008;19(25):1-8.

15. Bar-llan O, Albrecht RM, Fako VE, Furgeson DY. Toxicity assessments of multisized gold and silver nanoparticles in zebrafish embryos. Small. 2009;5(16):1897-1910.

16. Ji JH, Jung JH, Kim SS, et al. Twenty-eight-day inhalation toxicity study of silver nanoparticles in Sprague-Dawley rats. Inhal Toxicol. 2007;19(10):857-871.

17. Sung JH, Ji JH, Park JD, et al. Subchronic inhalation toxicity of silver nanoparticles. Toxicol Sci. 2009;108(2):452-461.

18. Takenaka S, Karg E, Roth C, et al. Pulmonary and systemic distribution of inhaled ultrafine silver particles in rats. Environ Health Perspect. 2001;109 Suppl 4:547-551.

19. Trop M, Novak M, Rodl S, Hellbom B, Kroell W, Goessler W. Silvercoated dressing acticoat caused raised liver enzymes and argyria-like symptoms in burn patient. J Trauma. 2006;60(3):648-652.

20. Vlachou E, Chipp E, Shale E, Wilson YT, Papini R, Moiemen NS. The safety of nanocrystalline silver dressings on burns: a study of systemic silver absorption. Burns. 2007;33(8):979-985.

21. Hoppe CE, Lazzari M, Pardiñas-Blanco I, López-Quintela MA. One-step synthesis of gold and silver hydrosols using poly(N-vinyl-2-pyrrolidone) as a reducing agent. Langmuir. 2006;22(16):7027-7034.

22. Gasparyan VK. Gold and silver nanoparticles in bioassay, cell visualization and therapy. Curr Clin Pharmacol. 2009;4(2):159-163.

23. Siddiqui TS, Jani A, Williams F, et al. Lanthanide complexes on Ag nanoparticles: designing contrast agents for magnetic resonance imaging. J Colloid Interface Sci. 2009;337(1):88-96.

24. Homan K, Shah J, Gomez S, et al. Combined Ultrasound and Photoacoustic Imaging of Pancreatic Cancer Using Nanocage Contrast Agents. Proc. of SPIE 2009;7177:71771M1-71771M6.

25. Vo-Dinh T, Wang HN, Scaffidi J. Plasmonic nanoprobes for SERS biosensing and bioimaging. J Biophotonics. 2010;3(1-2):89-102.

26. Sadauskas E, Wallin H, Stoltenberg M, et al. Kupffer cells are central in the removal of nanoparticles from the organism. Part Fibre Toxicol. 2007;4:10.

27. Cho WS, Cho M, Jeong J, et al. Acute toxicity and pharmacokinetics of 13 nm-sized PEG-coated gold nanoparticles. Toxicol Appl Pharmacol. 2009;236(1):16-24.

28. Semmler-Behnke M, Kreyling WG, Lipka J, et al. Biodistribution of 1.4- and 18-nm gold particles in rats. Small. 2008;4(12): 2108-2111.
29. Wunderlich G, Grüning T, Paulke BR, Lieske A, Kotzerke J. ${ }^{99 m}$ Tc labelled model drug carriers - labeling, stability and organ distribution in rats. Nucl Med Biol. 2004;31(1):87-92.

30. Zavaleta CL, Smith BR, Walton I, et al. Multiplexed imaging of surface enhanced Raman scattering nanotags in living mice using noninvasive Raman spectroscopy. Proc Natl Acad Sci U S A. 2009;106(32): 13511-13516.

31. Schipper ML, Cheng Z, Lee SW, et al. microPET-based biodistribution of quantum dots in living mice. J Nucl Med. 2007;48(9): $1511-1518$

32. de Jong WH, Hagens WI, Krystek P, Burger MC, Sips AJ, Geertsma RE. Particle size-dependent organ distribution of gold nanoparticles after intravenous administration. Biomaterials. 2008;29(12): 1912-1919.

33. Schnitzer JE. gp60 is an albumin-binding glycoprotein expressed by continuous endothelium involved in albumin transcytosis. Am J Physiol. 1992;262(1 Pt 2):H246-H254.

34. Testa JE, Chrastina A, Oh $\mathrm{P}$, et al. Immunotargeting and cloning of two CD34 variants exhibiting restricted expression in adult rat endothelia in vivo. Am J Physiol Lung Cell Mol Physiol. 2009;297(2): L251-L262.

35. Chrastina A, Valadon P, Massey KA, Schnitzer JE. Lung Vascular Targeting Using Antibody to Aminopeptidase P: CT-SPECT Imaging, Biodistribution and Pharmacokinetic Analysis. J Vasc Res. 2010; 47(6):531-543.

36. Lundh C, Lindencrona U, Schmitt A, Nilsson M, Forssell-Aronsson E. Biodistribution of free ${ }^{211} \mathrm{At}$ and ${ }^{125} \mathrm{I}$-in nude mice bearing tumors derived from anaplastic thyroid carcinoma cell lines. Cancer Biother Radiopharm. 2006;21(6):591-600.

37. Hussain SM, Hess KL, Gearhart JM, Geiss KT, Schlager JJ. In vitro toxicity of nanoparticles in BRL 3A rat liver cells. Toxicol In Vitro. 2005;19(7):975-983.

38. Smith BM, Zyromski NJ, Allison DC. Community-acquired methicillinresistant Staphylococcus aureus liver abscess requiring resection. Surgery. 2007;141(1):110-111.

39. Sangro B, Bilbao JI, Iñarrairaegui M, Rodriguez M, Garrastachu P, Martinez-Cuesta A. Treatment of hepatocellular carcinoma by radioembolization using 90Y microspheres. Dig Dis. 2009;27(2):164-169.

40. Sundram F, Chau TC, Onkhuudai P, Bernal P, Padhy AK. Preliminary results of transarterial rhenium-188 HDD lipiodol in the treatment of inoperable primary hepatocellular carcinoma. Eur J Nucl Med Mol Imaging. 2004;31(2):250-257.

41. Raoul JL, Boucher E, Roland V, Garin E. 131-iodine Lipiodol therapy in hepatocellular carcinoma. $Q \mathrm{~J} \mathrm{Nucl} \mathrm{Med} \mathrm{Mol} \mathrm{Imaging.} 2009$ 53(3):348-355.
International Journal of Nanomedicine

\section{Publish your work in this journal}

The International Journal of Nanomedicine is an international, peerreviewed journal focusing on the application of nanotechnology in diagnostics, therapeutics, and drug delivery systems throughout the biomedical field. This journal is indexed on PubMed Central,

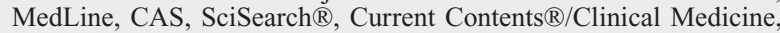

\section{Dovepress}

Journal Citation Reports/Science Edition, EMBase, Scopus and the Elsevier Bibliographic databases. The manuscript management system is completely online and includes a very quick and fair peer-review system, which is all easy to use. Visit http://www.dovepress.com/ testimonials.php to read real quotes from published authors. 